\title{
Effect of Expanding a Rectangular Tunnel on Adjacent Structures
}

\author{
Ya-Qiong Wang $\mathbb{D},{ }^{1}$ Wei-Kang Kong, ${ }^{2}$ and Zhi-Feng Wang $\mathbb{D}^{3}$ \\ ${ }^{1}$ Professor, School of Highway, Chang'an University, Xi'an 710064, China \\ ${ }^{2}$ Graduate Student, School of Highway, Chang'an University, Xi'an 710064, China \\ ${ }^{3}$ Associate Professor, School of Highway, Chang'an University, Xi'an 710064, China \\ Correspondence should be addressed to Zhi-Feng Wang; zhifeng.wang@chd.edu.cn
}

Received 12 July 2018; Revised 19 September 2018; Accepted 16 October 2018; Published 6 November 2018

Academic Editor: Venu G. M. Annamdas

Copyright ( 2018 Ya-Qiong Wang et al. This is an open access article distributed under the Creative Commons Attribution License, which permits unrestricted use, distribution, and reproduction in any medium, provided the original work is properly cited.

\begin{abstract}
The expansion of urban underpass has become the mainstream of development to cope with urban congestion, and the effect on adjacent existing structures during enlarging construction is also an important issue in the construction process. In order to better understand the influence of tunneling on adjacent structures, the pedestrian underpass expanding project above-crossing Xi'an Metro Line 1 was investigated. The aim was to analyze the deformation curves characteristics of adjacent structures by field observation of ground settlement, heave of existing tunnels, and settlement of piles. The results show that the ground settlement curve in the vertical direction of the underpass is similar to the shape of $\mathrm{V}$, and the maximum settlement appearing in the center line of underpass is $18.7 \mathrm{~mm}$. Due to the effect of existing tunnels on the ground deformation, the settlement curve in the parallel direction of the underpass is similar to the shape of $\mathrm{M}$. Above-crossing tunneling would cause the existing tunnels to heave, and the heave mainly occurs in the range of $-6 \mathrm{~m}$ to $12 \mathrm{~m}$ between the pedestrian tunnel face and the center line of each tunnel. The heave curve is similar to the shape of inverted $U$. The settlement of piles is linear with its axial stress and significantly affected by its location. The settlement curve of piles is similar to the shape of $S$ in two dimensions. On the basis of deformation curves, this paper presents some equations to describe the shape of V, M, inverted $\mathrm{U}$, and S, respectively, by the inverted Gaussian distribution curve, superimposed Gaussian distribution curve, Gaussian distribution curve, and arctangent function.
\end{abstract}

\section{Introduction}

Due to the demand of urban construction and highly congested urban, an increasing number of tunnels are being or have been constructed adjacent or above existing tunnels or building foundation to meet the increasing requirement of transportation. Meanwhile, there are also a numerous number of tunnels that need to be expanded urgently to meet existing operating demands. Surface deformation during and after construction is a considerable topic, and there will be many factors causing deformation [1-6]. Ground settlement induced by tunnel excavation has been studied extensively [7-14]. It is widely reported that the settlement curve for a single tunnel takes the shape of an inverted Gaussian distribution curve symmetrical to the tunnel axis at right angles [15]. Using a Gaussian distribution curve to describe the ground settlement curve was first proposed by Peck [7] and later verified by field and laboratory tests $[16,17]$. Byun $[18]$ conducted a large-scale model to investigate the ground behavior during construction of a new tunnel crossing beneath the existing tunnel. The interaction between tunneling in sand and surface structures is investigated by centrifuge to show the result that assuming a no-tension interface between the soil and the structure is essential to the soil-structure interaction [19]. Wang [20] conducted a FE analysis of surface settlement above a shallow tunnel in soft ground and examined the influence of soil creep, consolidation, and lining permeability.

Many previous studies examined the interaction between tunnels during construction of above-crossing tunnels by means of centrifugal and physical tests and the establishment of 3D FE models [21-23]. Liang [24] proposed a simplified analytical method for evaluating the behavior of underlying tunnels to obtain a better mechanical understanding of the above-crossing tunneling on the existing tunnels. Do et al. [25] performed a series of 3D numerical analyses to investigate the influences of the constructions 
process on two parallel and stacked tunnels. Choi and Lee [26] carried out a series of physical model tests to investigate the various factors which affect the mechanical behavior of the existing and new tunnels during the excavation. $\mathrm{Ng}$ [27] performed a series of $3 \mathrm{D} \mathrm{FE}$ analyses to investigate the interactions between large parallel twin tunnels in stiff clay by using the NATM. Kimmance [28] described the measured results of existing tunnels and found that tunnel settlement generally occurred when a new tunnel was constructed beneath it.

Tunneling under the foundations of structures is becoming more common because of the lack of available space for infrastructure. As the anisotropy of loess increases the uncertainty of the effect of tunneling on adjacent structures [29-33], the interaction between newly constructed tunnels and existing piled foundation becomes a significant issue [34-38]. Lueprasert [39] recommended an assessment method to assess the impacts of an adjacent pile under loading on a tunnel for establishing a preventive measure in the design stage. Marshall [40-43] introduced an efficient analytical approach to estimate the effect of constructing a new tunnel on an existing pile. $\mathrm{Ng}$ [44] carried out a series of threedimensional centrifuge model tests to study the effects of twin tunneling activity on existing single pile and found that the settlement of pile induced by excavation is closely related to the relative depth of pile. Lee and Bassett [45] presented influence zones based on the normalized pile tip settlement from both model tests and numerical analysis, and Selemetas [46] suggested influence zones from field observation.

In previous studies, there were few cases of the introduction and studies of above-crossing tunneling. In addition, the case of rectangular tunneling is almost nowhere to be found. Because the geometric symmetry of the rectangular tunnel is worse than that of the circular tunnel and stress concentration often occurs at the angle of structures, the construction of the rectangular tunnel may have a greater impact on the adjacent structures. Based on the case of Xi'an underpass expanding project abovecrossing Metro Line 1, this paper studies the effect of rectangular tunneling on the deformation of adjacent structures through a large number of measured data and analyzes the deformation law. The aim was to provide experience and basis for similar projects in the future.

\section{Project Overview}

2.1. Brief Description of Project. The project along to West Changle Road is located in the central section of Xi'an, China. A plan view and two cross-sectional views of adjacent structures of the project are shown in Figures 1, 2, and 3, respectively. The existing tunnels in service run east-west and belong to Line 1 of Xi'an Metro. They are horizontally parallel and referred to "North Tunnel" and "South Tunnel". The existing tunnels were excavated by the shield method. The clearance between them is $9.0 \mathrm{~m}$, and the internal and external radii of the lining are approximately equal to $2.7 \mathrm{~m}$ and $3.0 \mathrm{~m}$, respectively. The overburden depth of the existing tunnels crown is about $16.4 \mathrm{~m}$.

The existing pedestrian underpass is $60.0 \mathrm{~m}$ long, which is divided by two tunnels into a north part of $12.0 \mathrm{~m}$, a middle

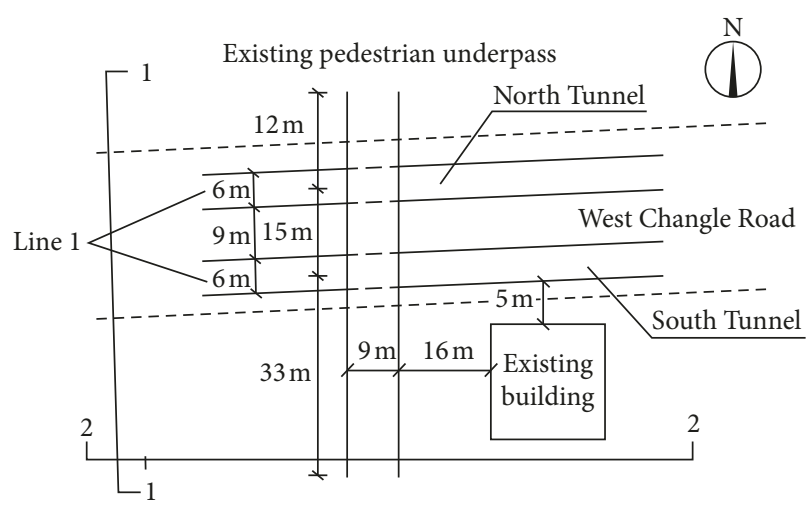

Figure 1: Plan view of the project.

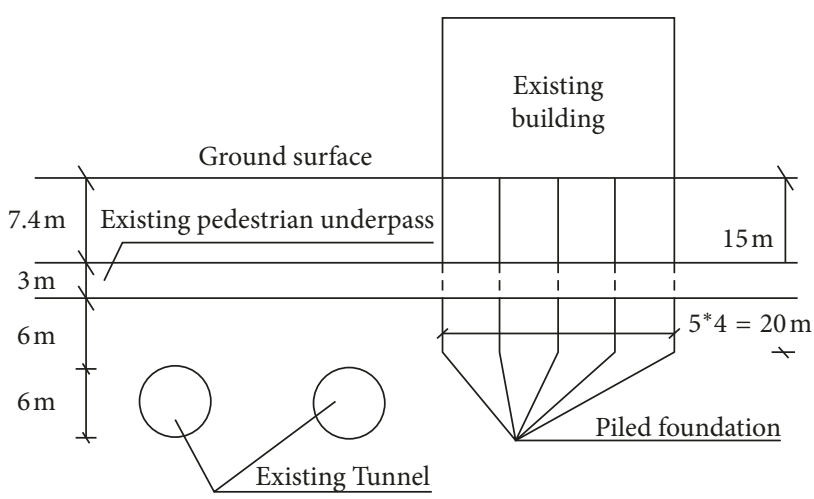

FIgURE 2: Section view of 1-1.

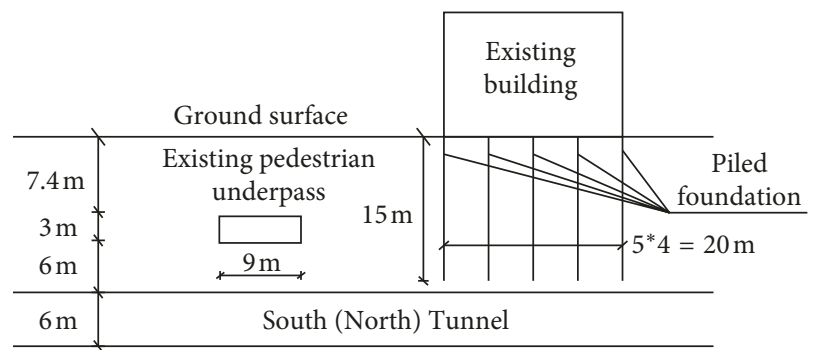

FIgURE 3: Section view of 2-2.

part of $15.0 \mathrm{~m}$, and a south part of $33.0 \mathrm{~m}$. The clear height and width are $3.0 \mathrm{~m}$ and $9.0 \mathrm{~m}$, respectively, and the depth is $7.4 \mathrm{~m}$. The thickness of the lining is $500 \mathrm{~mm}$. The pedestrian underpass runs south-north and was constructed before two tunnels. Due to the rapid development of Xi'an city and the increasing of population density in this area, the space of the pedestrian underpass is not enough to meet operational needs and it needs expansion referring to urban construction planning. A new pedestrian underpass construction scheme expands the clear height and width to $4.2 \mathrm{~m}$ and $12.0 \mathrm{~m}$, respectively, and the depth is unchanged. The excavation zone is divided into three steps, and the sequences are referred as the number of 1,2 , and 3 . The thickness of the primary and secondary lining is $200 \mathrm{~mm}$ and $300 \mathrm{~mm}$, and the total thickness is the same as before. Specific characteristics dimensions are shown in Figure 4(a). Construction scheme and sequence are shown in Figure 5(b). 


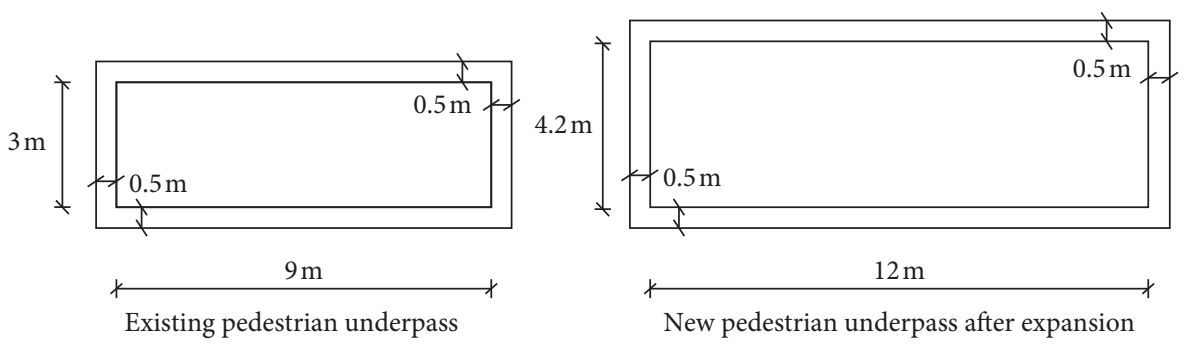

(a)

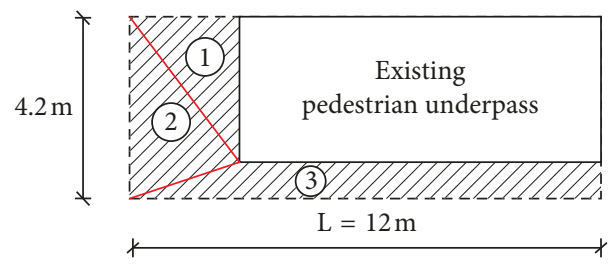

(b)

FIgURE 4: (a) Characteristic dimensions of existing and new pedestrian underpass; (b) construction scheme and sequence.

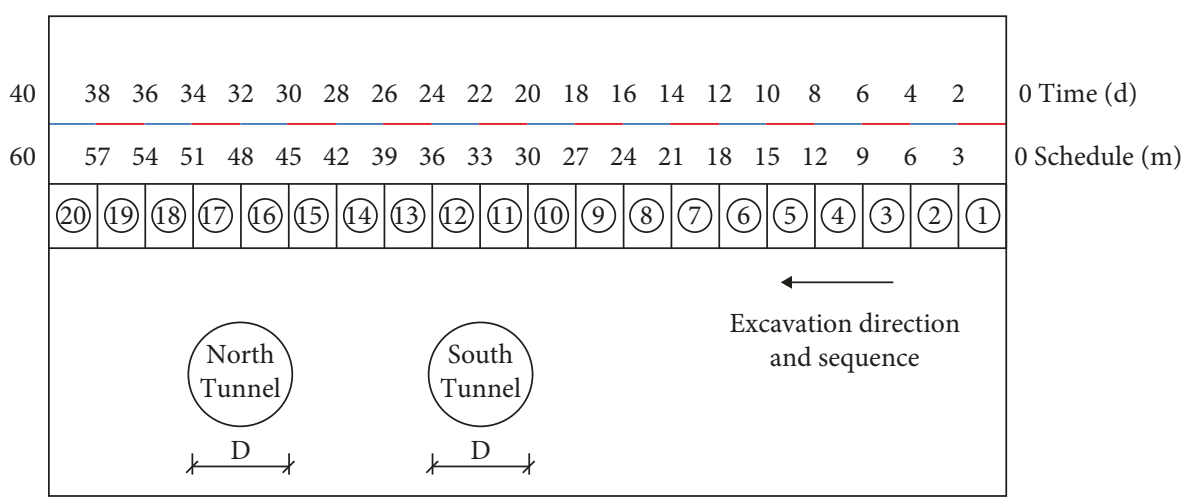

FIGURE 5: Excavation sequence of new pedestrian underpass.

An existing building with piled foundation is located in the southeast corner formed by pedestrian underpass and two tunnels. The clearance between building and South Tunnel is approximately $5.0 \mathrm{~m}$, and the clear distance between building and pedestrian underpass is about $16.0 \mathrm{~m}$. Piles could be assumed to arrange in a square with sides length of $20.0 \mathrm{~m}$. The length and diameter of each pile are $15 \mathrm{~m}$ and $0.6 \mathrm{~m}$. Piles are arrayed in a five-by-five formation which means the distance between two adjacent piles is $5.0 \mathrm{~m}$.

According to the feasibility study and economic and technological comparison, the construction sequence from south to north is selected to cater to the surrounding environment. Each sequence includes excavation, installation of the primary lining, and the secondary lining. The length of each tunneling process is $3.0 \mathrm{~m}$, and the time between two adjacent processes is 2 days. The entire project is divided into 20 sequences and lasts 40 days, as shown in Figure 5.

2.2. Site Conditions. A typical geological profile of the project is shown in Figure 6. The subsurface ground on the site consists of backfill $(0.0 \sim 1.9 \mathrm{~m})$, new loess $(0.5 \sim 5.5 \mathrm{~m})$, saturated loess $(3.5 \sim 17.3 \mathrm{~m})$, paleosol $(13.2 \sim 18.5 \mathrm{~m})$, old loess $(15.3 \sim 21.9 \mathrm{~m}$ ), and silty clay (maximum $39.4 \mathrm{~m}$ ). The groundwater table fluctuates seasonally between $5.4 \mathrm{~m}$ and $6.8 \mathrm{~m}$, and the groundwater table is assumed to be $6.0 \mathrm{~m}$ deep in these analyses.

2.3. Monitoring Program. During the expanding process, the deformation of the ground, existing tunnels, and piles are monitored. The layout of the monitoring points on the existing tunnels is shown in Figure 7. The letters "NMP" and "SMP" indicate "North Tunnel Monitoring Point" and "South Tunnel Monitoring Point". The points are arranged by the distance of $6 \mathrm{~m}$. The layout and numbering rules of the pile are shown in Figure 8, and the position of the monitoring points is at the top of each piled foundation. The layout of the monitoring points on the ground surface is shown in Figure 9. The letters "GMP" of the monitoring point mean "Ground Monitoring Points". The points are arranged vertical to the underpass by the distance of $6 \mathrm{~m}$. Furthermore, 5 monitoring points are laid parallel to the 


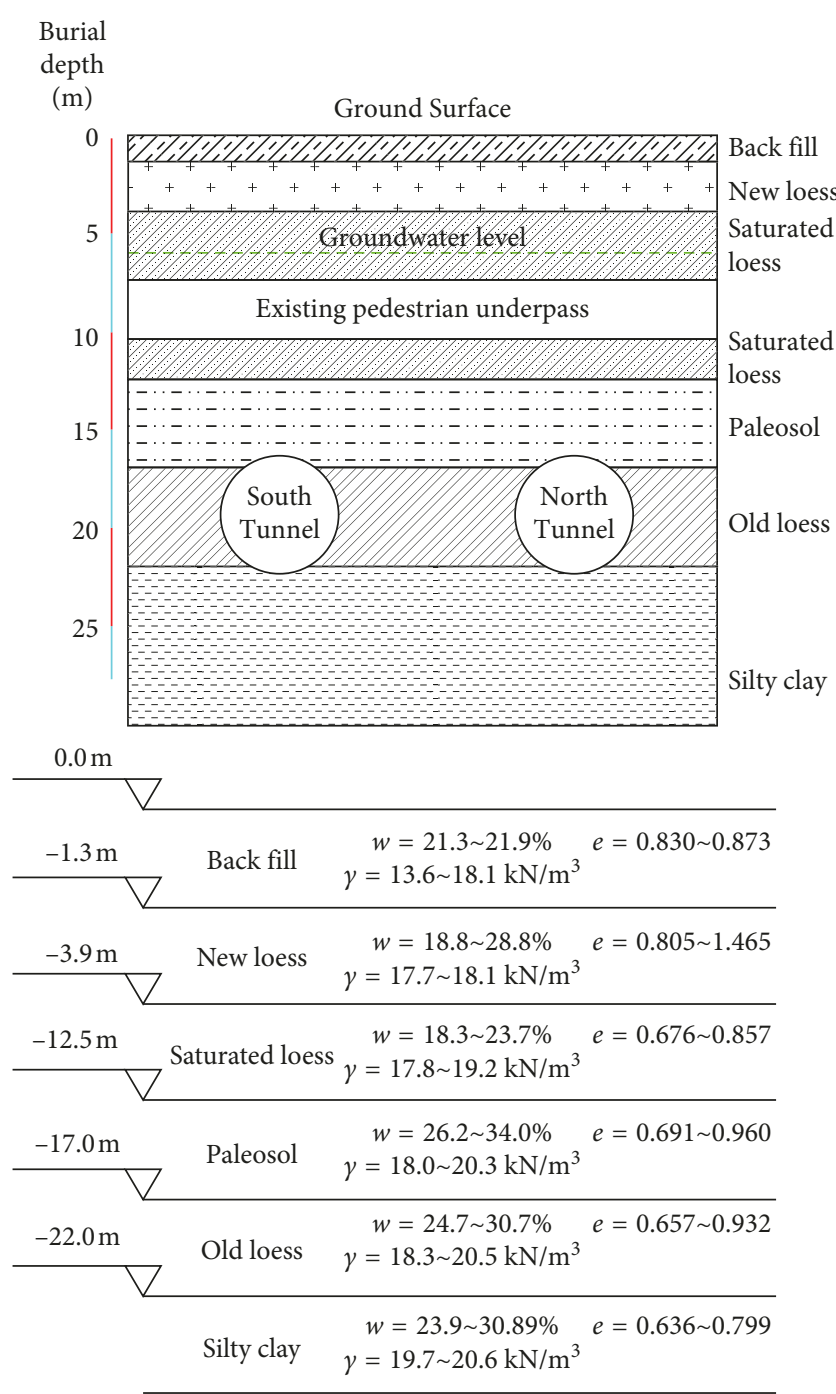

Figure 6: Typical geological profile of the project.

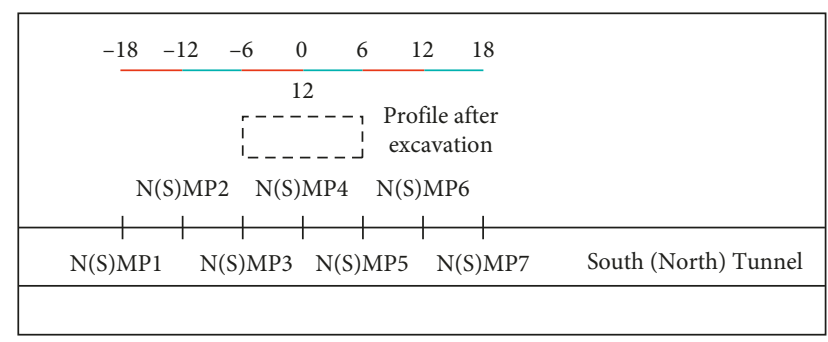

FIgURE 7: Layout of the monitoring points along the tunnels.

underpass to match the key points or sequences in the project which are shown by red lines.

\section{Field Observation Results}

3.1. Ground Surface Settlement. After screening a large number of original ground surface settlement data, correcting errors, and fitting process, the settlement curve of

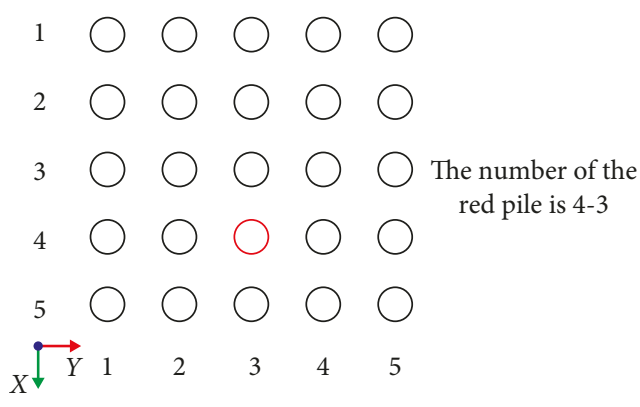

Figure 8: Layout of piles.

ground monitoring points during the expanding process is shown in Figures 10 and 11. The layout of the monitoring points GMP1 7 in Figure 11 references the location of GMP4- 5 because they have the maximum settlement in this analysis. Except monitoring during construction, a measurement was also carried out 20 days after the completion of construction. We can conclude that the ground settlement could be divided into four stages. Minor disturbance stage: when the pedestrian tunnel face has not crossed monitoring points and the distance between them is more than $-3 \mathrm{~m}$, the overall trend of settlement increases slightly with the construction. Rapid development stage of settlement: when the pedestrian tunnel face is close to and further crossing the monitoring points, the ground settlement develops rapidly during this expanding process, and this phenomenon mainly occurs in the scope of $-3 \mathrm{~m}$ to $9 \mathrm{~m}$ relative to the monitoring points. The maximum settlement rate can reach $1.83 \mathrm{~mm} / \mathrm{d}$. Slow development stage of settlement: the pedestrian tunnel face has a certain distance from the monitoring points, the underpass lining has a certain strength initially, the influence of construction gradually decreases, and the deformation rate slows down. At this time, the settlement value of each monitoring point has reached $92 \%$ of the maximum settlement. Settlement stability stage: the pedestrian tunnel face is far away from the monitoring points, the strength of lining is formed, the surface deformation tends to be stable, and the disturbance of the surrounding soil is stopped due to expansion was finished. The same settlement characteristics also appeared in other sections of Xi'an subway construction [47].

The maximum settlement of some typical monitoring points of the ground surface is shown in Figure 12. The ground settlement curve in the parallel direction of the underpass is similar to the shape of $\mathrm{M}$. As shown in Figure 12(a), the point GMP4-4 is about $15 \mathrm{~m}$ ahead the point GMP4-2 along the tunneling direction, which means GMP4-4 was excavated 10 days earlier than GMP4-2. Both monitoring points are located directly above existing tunnels, but the settlement of GMP4-4 is about $1.25 \mathrm{~mm}$ less than GMP4-2. This phenomenon is mainly ascribable to the reason that the effect of tunneling makes the surrounding soil disturbed and the stiffness decreased. As GMP4-2 is disturbed longer, its settlement is higher. Furthermore, the settlement of GMP4-2 and 4-4 is less than that of GMP4-1, $4-3$, and $4-5$, and this phenomenon is mainly ascribable to the fact that the existing tunnels could support the soil to prevent the surface from settling. 


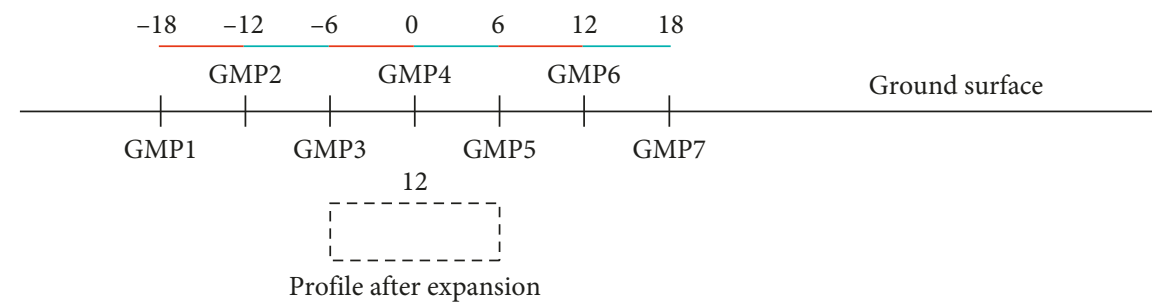

(a)

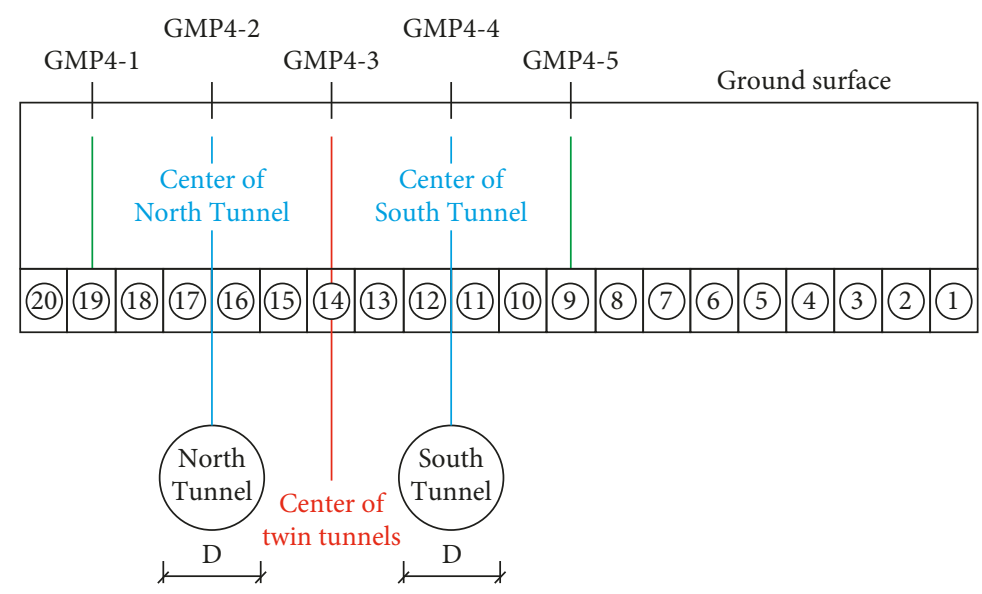

(b)

FIGURE 9: Layout of the monitoring points on the ground surface.

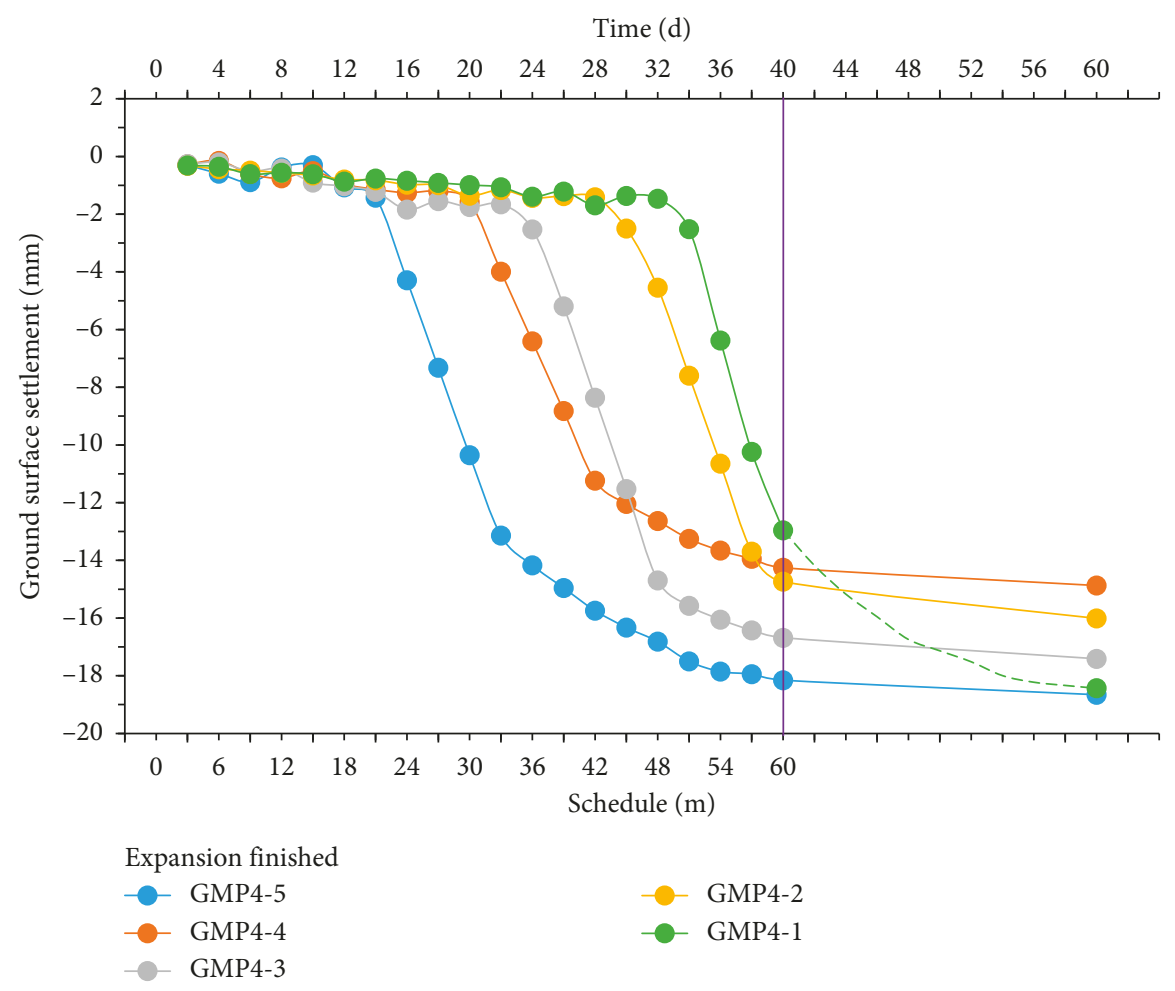

Figure 10: Settlement of GMP4-1 5 during the expanding.

A comparison of the settlement of the monitoring points (GMP1 7) shows that the ground settlement curve displays an approximately symmetrical single-trough shape $\mathrm{V}$ in the vertical direction of the underpass. The maximum ground settlement occurs within the scope of the underpass, and the peak appears at the center line of the underpass. 


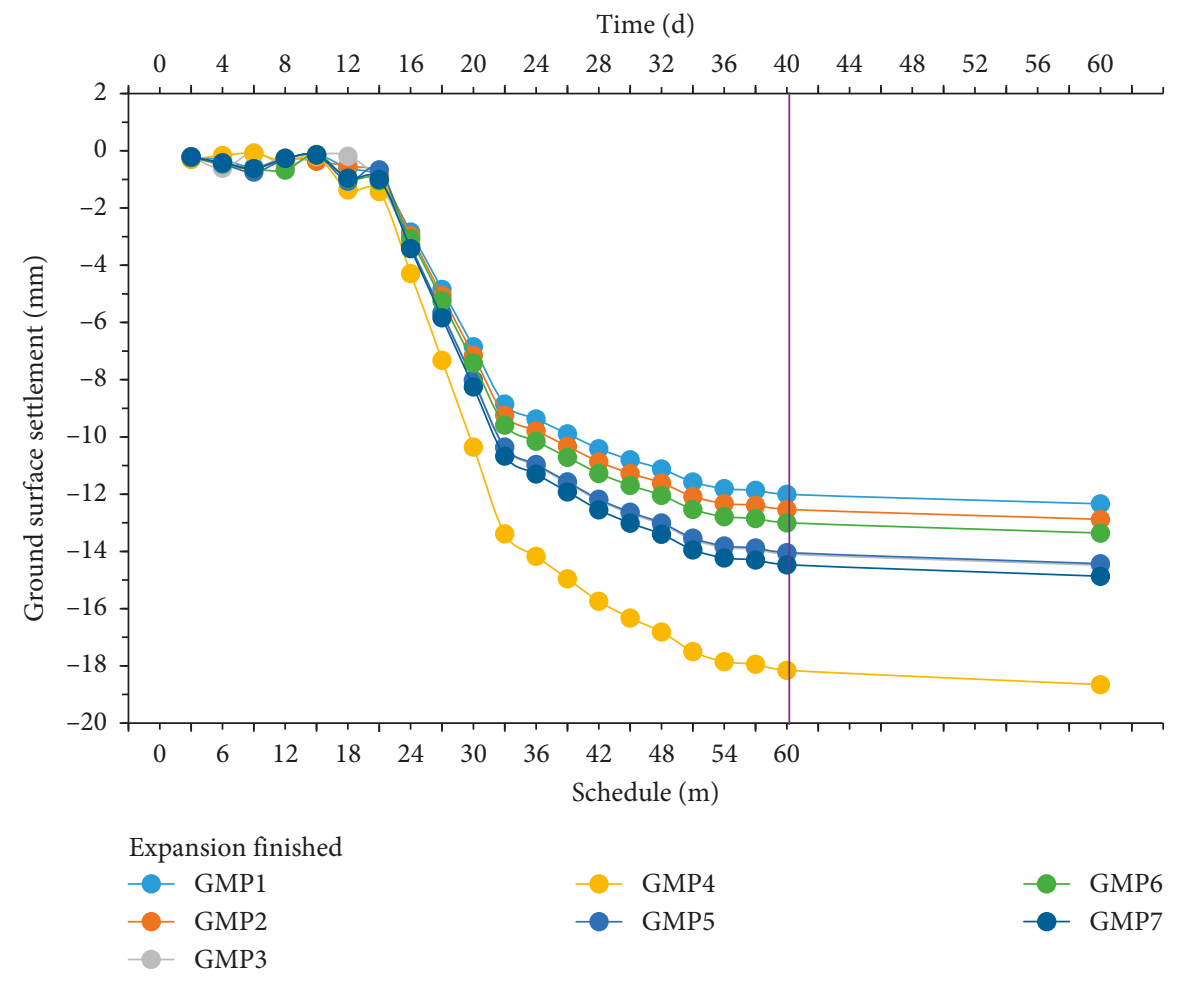

FIGURE 11: Settlement of GMP1 7 during the expanding.

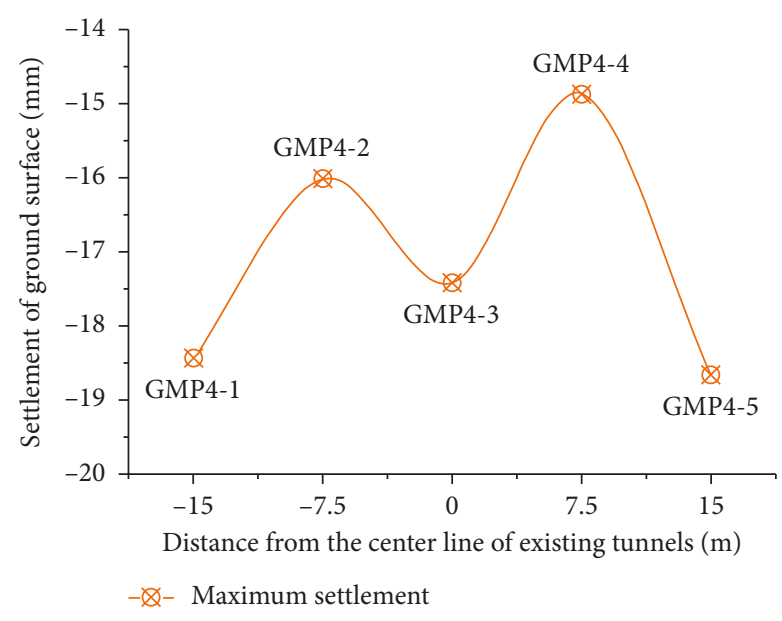

(a)

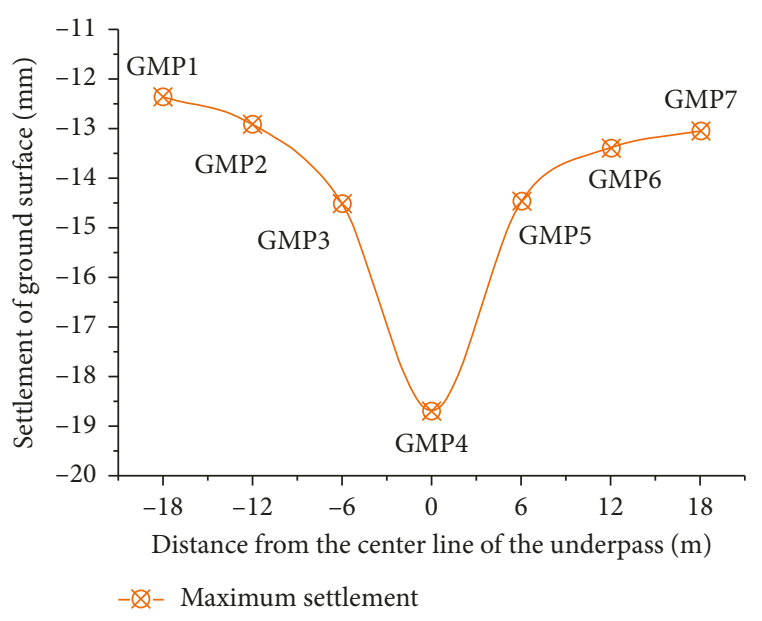

(b)

FIGURE 12: Settlement of the ground surface: (a) settlement of GMP4; (b) settlement of GMP1-7.

3.2. Existing Tunnels Heave and Pressure. The development of the existing tunnels heave and the maximum heave for some typical monitoring points are shown in Figure 13. Due to the influence of the construction direction, the pedestrian tunnel face crosses ST first, which leads to the phenomenon that ST heave curve slope increases earlier than NT. The phenomenon of the heave difference between ST and NT is mainly ascribable to the reason that the surrounding soil is disturbed when the pedestrian tunnel face reaches existing tunnels. Soil looseness would cause changes of tunnel linings stress, which is manifested by the occurrence of heave. Since the ST is affected by tunneling for a longer time, the maximum heave of ST is larger than NT.

When the distance between the pedestrian tunnel face and the center line of ST is more than $6 \mathrm{~m}(x<-13.5 \mathrm{~m})$, the effect of tunneling on the two existing tunnels is basically the same. For ST, when the distance between pedestrian tunnel face and its center line is less than $6 \mathrm{~m}(x>-13.5 \mathrm{~m})$, the heave of ST increases rapidly, and the tunneling effect would continue until the pedestrian tunnel face exceeds the center line about $12 \mathrm{~m}(x<4.5 \mathrm{~m})$. Then, the heave tends to be stable, and $93 \%$ of the total heave has been completed. For NT, the heave 


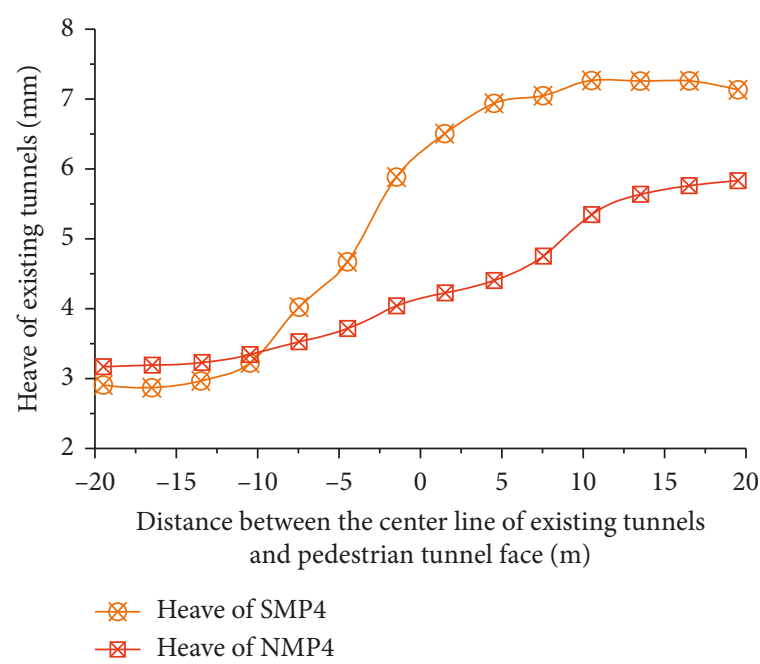

(a)

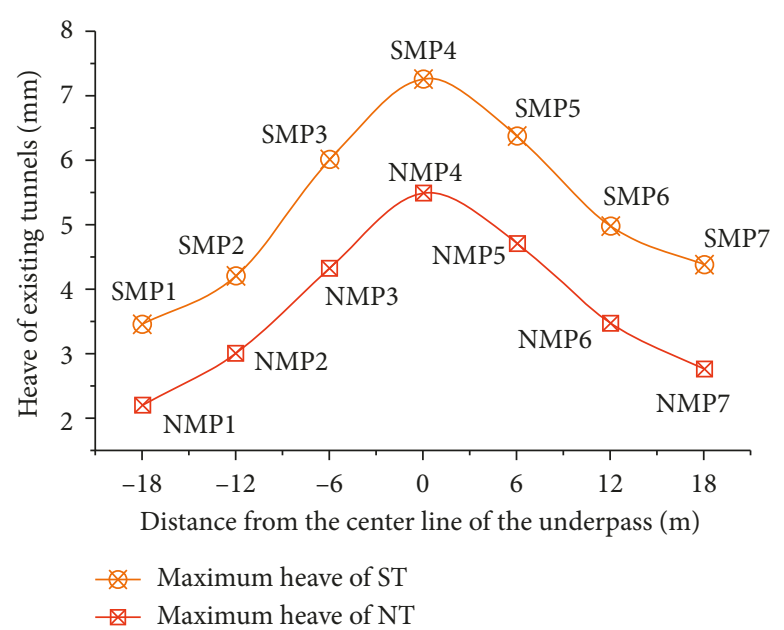

(b)

Figure 13: Heave of existing tunnels: (a) heave of the tunnels; (b) heave of monitoring point.

curve has the same turning points as ST. The heave rate increases when the distance between pedestrian tunnel face and its center line is less than $6 \mathrm{~m}(x>1.5 \mathrm{~m})$, and the deformation tends to be stable when the pedestrian tunnel face crosses the NT center line about $12 \mathrm{~m}(x<19.5 \mathrm{~m})$.

A comparison of the heave of the monitoring points (NT and ST of MP1 7) shows that the heave of existing tunnels displays an approximately symmetrical single-trough inverted shape $U$. And the maximum heave of tunnels occurs at the center line of the underpass.

The final stress variation distribution of the seven monitoring points of existing tunnels studied in this paper is shown in Figure 14. It is well known that the change of lining stress is mainly caused by the deformation of tunnels. The tunneling behavior will be the deformation of the surrounding soil around the existing tunnels and reduce the constraint on it. Monitoring points $\mathrm{N}(\mathrm{S}) \mathrm{MP} 1$ are selected to study the stress distribution of NT and ST. Figure 13(a) clearly shows that the difference in the displacement of two tunnels results in a phenomenon that the stress at the crown of the ST is greater than the stress at the NT. Moreover, the stress variation of the inner edge of the existing two tunnels is smaller than the stress variation of the outer edge. The reason is that the existence of the existing tunnels reduces the influence of expansion disturbances on the soil between two tunnels, and the development of the lining stress is restricted, while the outer edge is subject to larger influences. The maximum stresses of ST and NT are selected from figures, respectively, and the trend of the variation is to rise first (as indicated by $\mathrm{N}(\mathrm{M}) \mathrm{MP} 1 \sim 4$ ) and then decrease (as indicated by $\mathrm{N}(\mathrm{M}) \mathrm{MP} 4 \sim 7)$. The change also reflects the heave deformation law of existing tunnels in Figure 13(b).

3.3. Piled Foundation Settlement and Pressure. Figures 15 and 16 show the three-dimensional distribution of the final settlement value and the axial stress of piles, respectively. Obviously, for 5-1 5-5, as the pile on the left side is closer to the underpass, the disturbance during the construction process has a greater impact on it, causing the left pile to generate greater axial stress than the right pile (as shown in Figure 16) and resulting in larger settlement. For 1-1 1-5, the tunneling direction is parallel to the direction of pile arrangement, so the settlement value of the left pile should be considered due to the longer time affected by tunneling. In addition, the settlement of pile has a linear relationship with the value of axial stress in pile, as shown in Figure 17. Also, the maximum settlement of piles 5-1 5-5 and 1-1 1-5 is shown in Figure 18. Both the settlement curve of piles in $Y$ plane (orange curve) and in $X$ plane (red curve) are similar to the shape of $\mathrm{S}$.

\section{Discussion}

4.1. Ground Settlement. According to the monitoring data in Section 3.1, we can construct the transverse settlement curves of the ground surface. The magnitude and shape of a settlement curve are influenced by multiple factors such as tunnel dimensions and buried depth. Therefore, it is difficult to quantify every parameter affecting ground surface settlement. It is widely reported that the settlement curve for a single tunnel takes the shape of an inverted Gaussian distribution curve symmetrical to the tunnel axis. Using a Gaussian distribution curve to describe ground settlement curve was first proposed by Peck [7] and later verified by field and laboratory tests [17]. The shape of the settlement curve can be described by using the following equation:

$$
S=S_{\max } \cdot \exp \left[\frac{-x^{2}}{\left(2 i^{2}\right)}\right],
$$

where $x$ is the distance from the central line of a tunnel, $i$ (or trough width) is the distance from the tunnel center line to the inflection of the trough, and $S_{\max }$ is the maximum settlement.

In this section, we try to use the proposed Gaussian distribution curve to estimate the settlement curve of the 

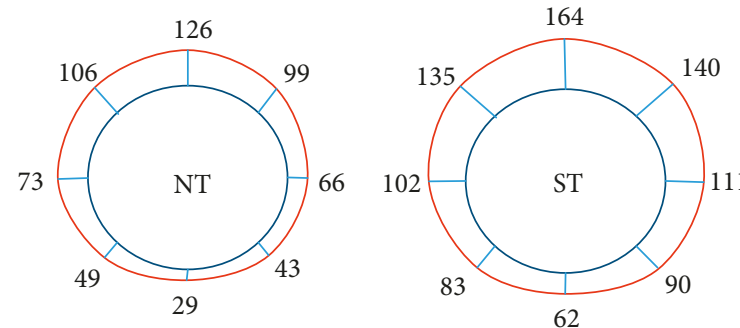

Tunnel linings stress of $\mathrm{N}(\mathrm{S}) \mathrm{MP} 1$ section $(\mathrm{kPa})$
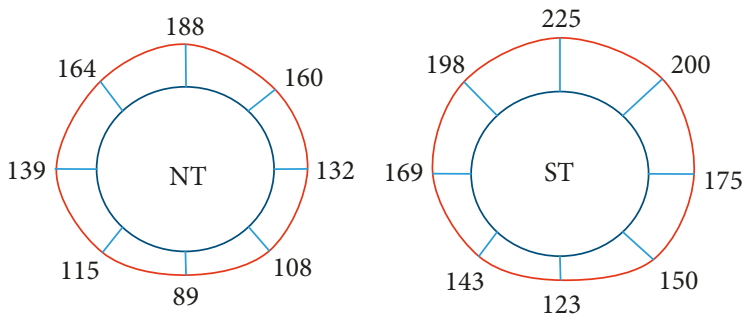

Tunnel linings stress of N(S)MP3 section $(\mathrm{kPa})$
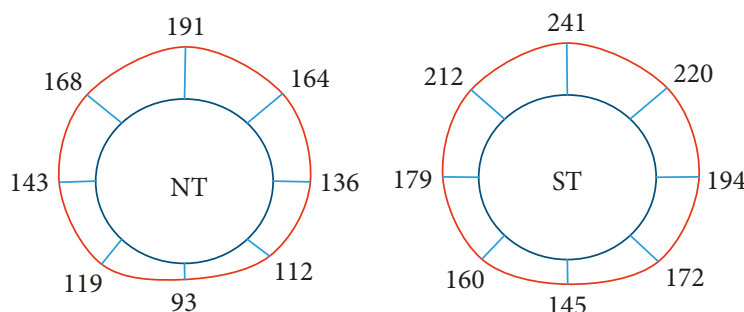

Tunnel linings stress of N(S)MP5 section $(\mathrm{kPa})$
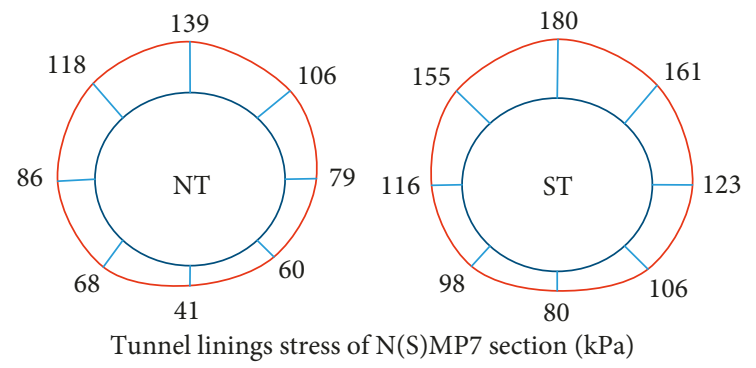

Figure 14: Stress distribution in linings of existing tunnels.
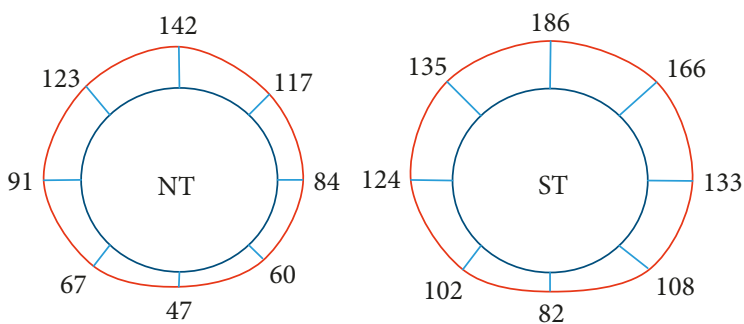

Tunnel linings stress of N(S)MP2 section ( $\mathrm{kPa})$
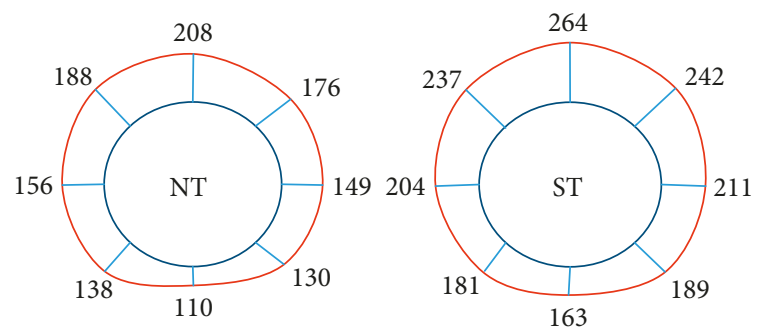

Tunnel linings stress of N(S)MP4 section (kPa)
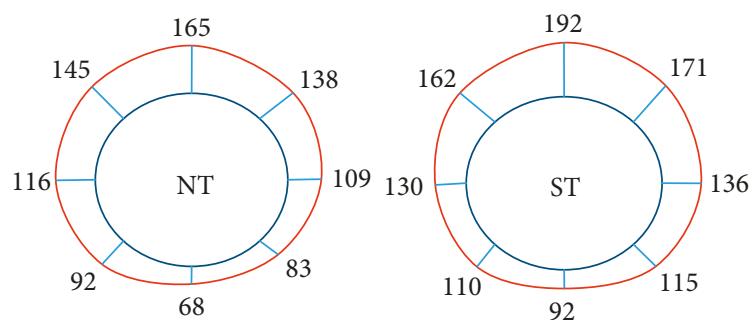

Tunnel linings stress of N(S)MP6 section ( $\mathrm{kPa})$

NT $=$ North tunnel

ST $=$ South tunnel

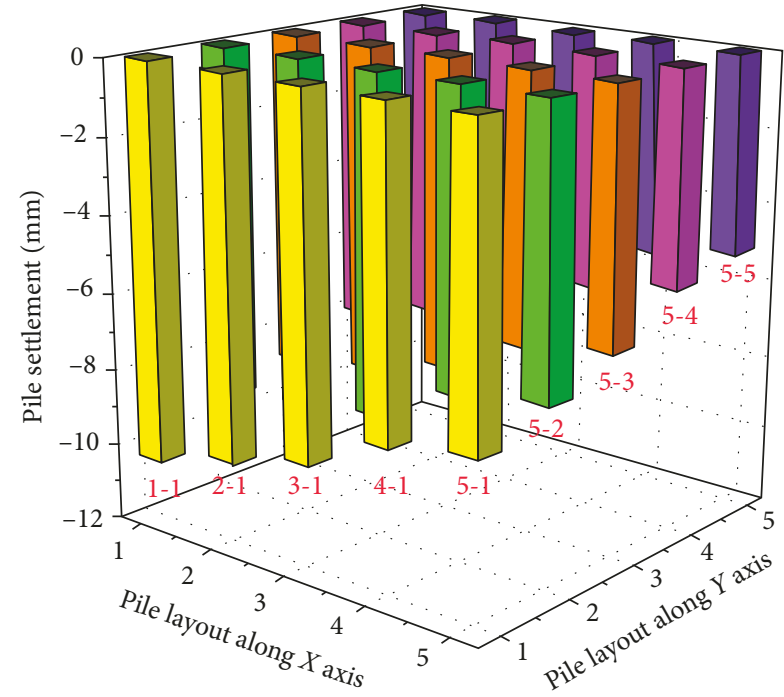

Figure 15: Settlement of piled foundation.

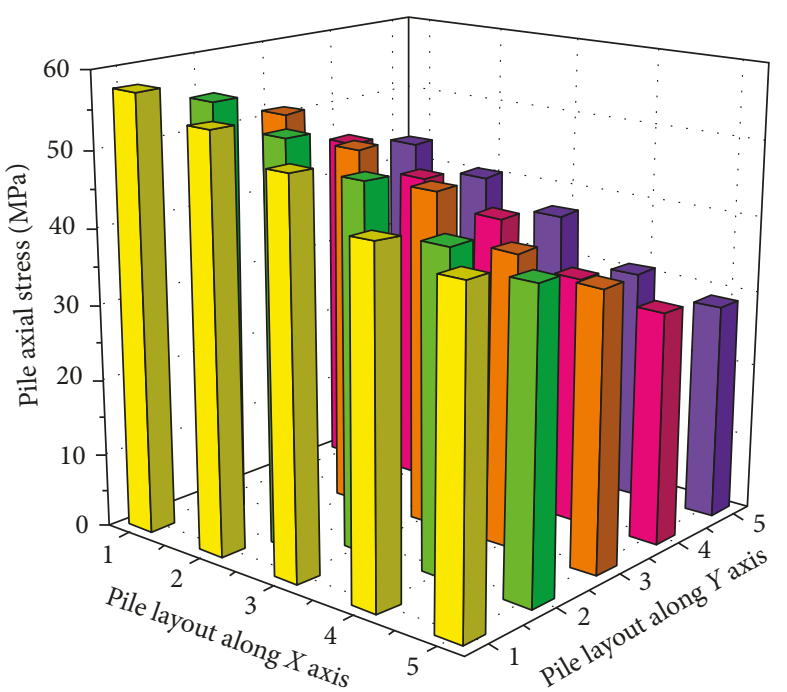

Figure 16: Axial stress distribution of piled foundation. 


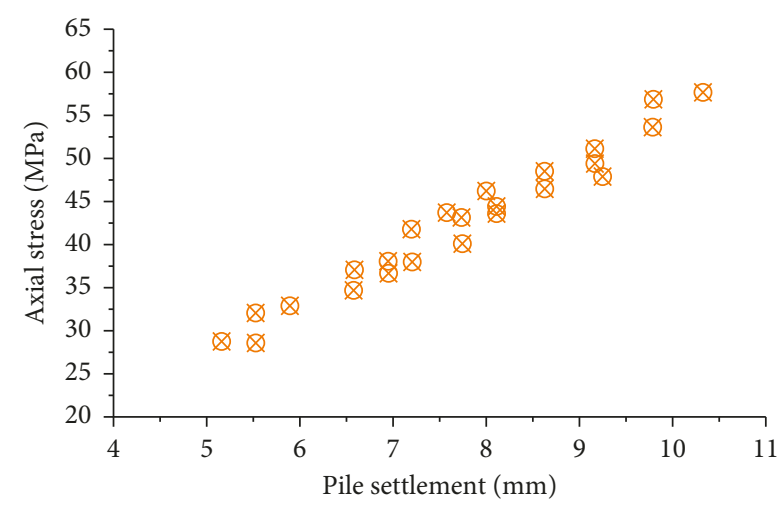

FIGURE 17: Relationship between pile settlement and axial stress.

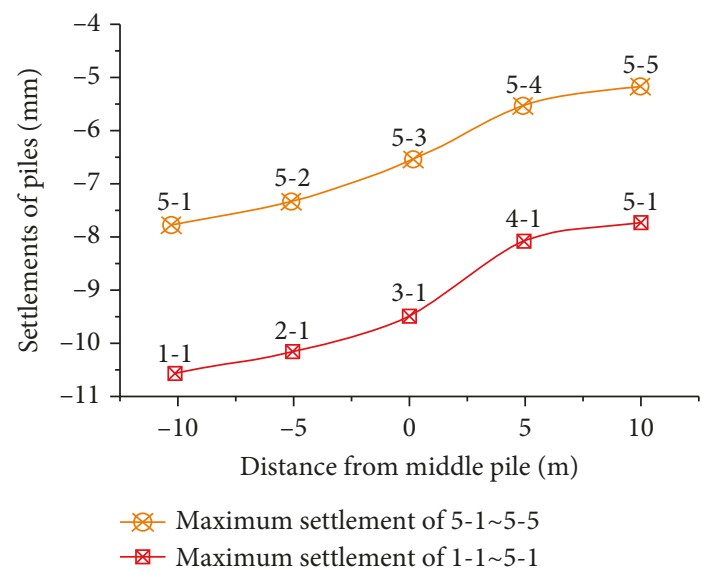

FIGURE 18: Settlement of piles.

ground surface under the effect of enlarging the existing rectangular underpass. As shown in Figure 12(b), the maximum settlement of the ground surface $S_{\max }=18.693 \mathrm{~mm}$. After many comparisons and attempts and based on the principle that the integer is easy to estimate, $i=12$ is determined. The calculation result is shown in Figure 19. It can be seen from the figure that, within the range of $\pm 12 \mathrm{~m}$ from the center line of the underpass, the results calculated by Formula (1) are well fitted with the results of the field observation, which indicates that the formula is available within a certain range of the effect of tunneling on the ground surface.

The reason of errors at both ends of the curve in Figure 19 is the geometric properties of the rectangular tunnel. As the formula is based on the circular tunneling, the stress concentration at the corner of the rectangular tunnel will lead to different effects from the circular tunneling.

In previous reports, many studies on the ground settlement induced by parallel tunneling were introduced $[48,49]$. A common practice is to superpose the independent transverse settlement curves calculated for each individual excavation to obtain the final accumulative settlement curve. The shape of the settlement curve can be described by using the following equation:

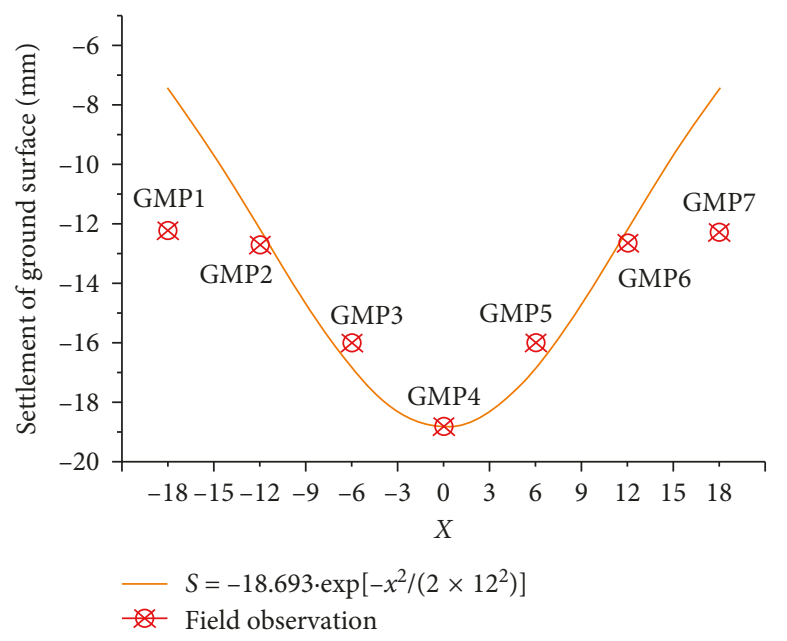

FIGURE 19: Calculation results and settlement value of GMP1 7.

$$
S=S_{\max 1} \cdot \exp \left[-\frac{(x+L / 2)^{2}}{2 i_{1}^{2}}\right]+S_{\max 2} \cdot \exp \left[-\frac{(x-L / 2)^{2}}{2 i_{2}^{2}}\right]
$$

where the subscript numbers 1 and 2 stand for the first tunnel excavated and the second tunnel excavated and $L$ is the horizontal distance between the central lines of the twin tunnels.

This calculation method has been proved to be suitable for laboratory tests $[49,50]$, and it has also been used by researchers $[15,51]$. However, for the case of analyzing the ground settlement caused by single tunnel construction under the effect of existing two tunnels, this method has not been adopted. In this study, the ground settlement of GMP4$1 \sim 5$ was calculated by using Formula (2). In order to facilitate the study, referring to the characteristic of the curve, all values are fitted after adding 19. It is found that when $S_{\max 1}=3 \mathrm{~mm}, S_{\max 2}=4.3 \mathrm{~mm}, i_{1}=4.5$, and $i_{2}=4$, the curve fits well. And then all values of the fitted curve minus 19 to return to the original value. The calculation result is shown in Figure 20.

4.2. Heave of Existing Tunnels. By reviewing literatures [52-56], minimal attention has been given to the effects of above-crossing tunnel construction on the underlying existing tunnels. Chen [57] and Ding [58] carefully reported the monitoring results of the longitudinal vertical displacements of the exiting Metro Line-2 tunnels due to the abovecrossing of Metro line- 8 twin tunnels in Shanghai. The heave of the exiting tunnel was observed during and after abovecrossing tunnel excavation. After observing the characteristics of the heave curve shown in Figure 13(b), we can find that it could also be described by the Gaussian distribution curve reasonably, which has also been proposed by Zhu [59].

The heave curve of two existing tunnels is analyzed by Formula (1). Using the same method as above, $S_{\max }=$ $7.26 \mathrm{~mm}$ and $i=12$ were taken in South Tunnel, and $S_{\max }=$ $5.49 \mathrm{~mm}$ and $i=12$ were taken in North Tunnel. The calculation results are shown in Figure 21. The same 


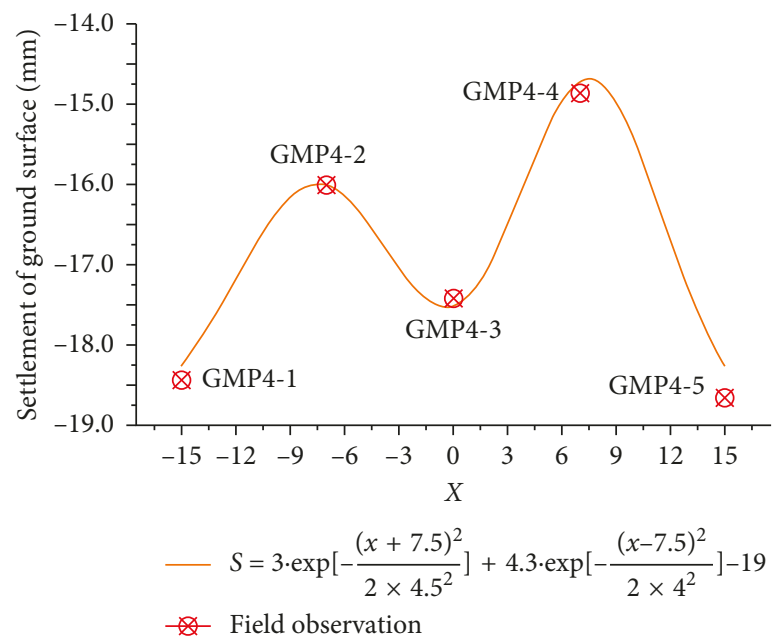

FIGURE 20: Calculation results and settlement value of GMP4-1 5.

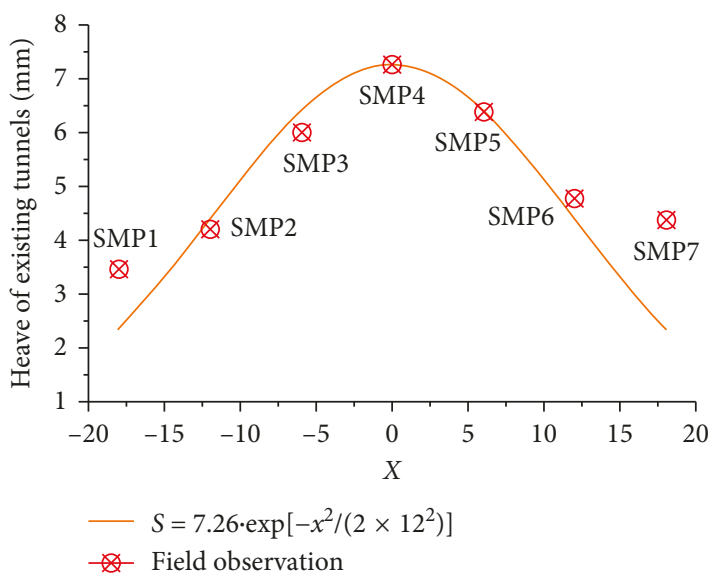

(a)

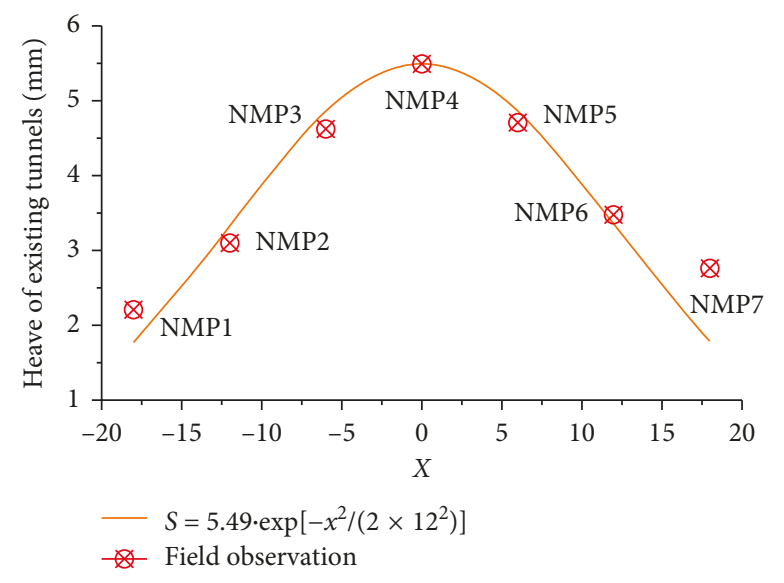

(b)

FIGURE 21: Calculation results and heave of existing tunnels: (a) calculation results and heave value of SMP1 7; (b) calculation results and heave value of NMP1 7.

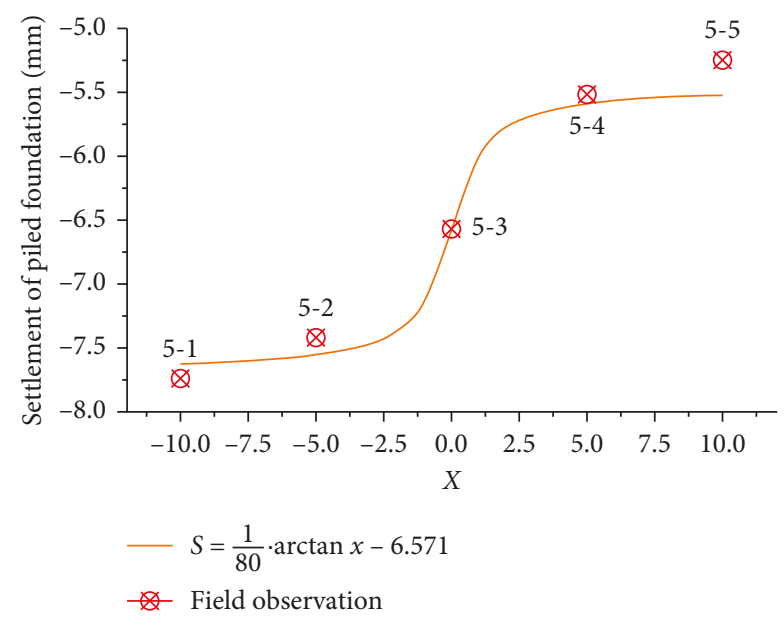

(a)

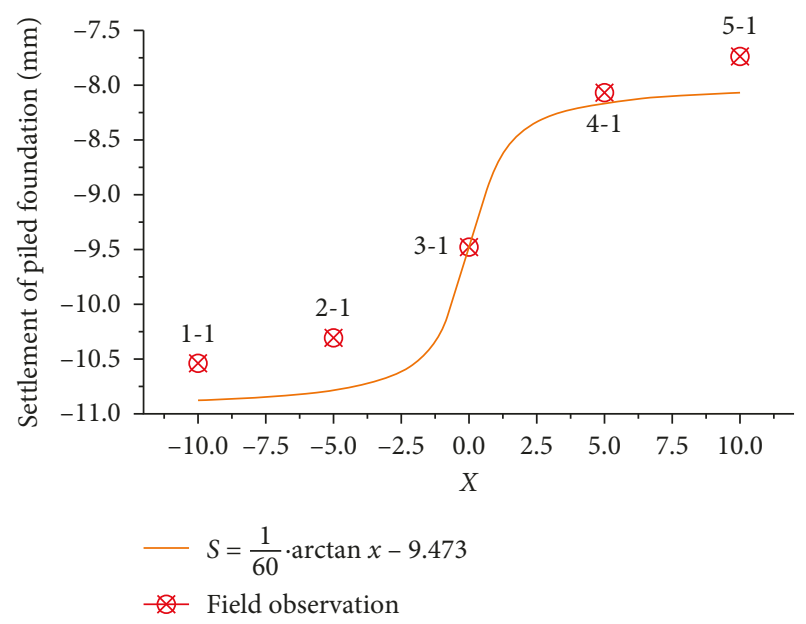

(b)

FIGURE 22: Calculation results and settlement of piled foundation: (a) calculation results and field observation of 5-1 5-5; (b) calculation results and field observation of 1-1 5-1. 
characteristics as ground settlement occurred, and the error of the fitting curve was acceptable within a range of $\pm 12 \mathrm{~m}$ from the central line of underpass, but beyond this range, the deviation was larger. This phenomenon can also be considered as the effect of stress concentration at the corner of the rectangular tunnel during tunneling.

4.3. Settlement of Piles. In this paper, arctangent function is proposed to be used to describe the settlement characteristics of piles. The shape of the settlement curve can be described by using the following equation:

$$
S=\mu \cdot \arctan x-H,
$$

where $\mu$ is a proportional coefficient (unit is $\mathrm{mm} /{ }^{\circ}$ ), $x$ is the distance from the central pile, $H$ is the settlement value of the central pile, and the degree measure is used in arctangent function. The fitting results of piles settlement are shown in Figures 22(a) and 22(b), respectively. $\mu=1 / 80$ and $H=6.571$ were taken in piles of 5-1 5-5, and $\mu=1 / 60$ and $H=9.473$ were taken in piles of 1-1 5-1. According to the spatial distribution of piles, the layout of piles numbered 5-1 5-5 is vertical to the underpass tunneling, so the settlement of piles is only affected by the single factor of spatial position, and the fitting curve is in good agreement with the field observation data, as shown in Figure 22(a). However, the layout of piles numbered 1-1 5-1 is parallel to the underpass tunneling, so the settlement of piles is no longer only affected by the location, and the time of each pile affected by tunneling becomes the main factor. A variety of factors lead to a large difference between the field observation data and the fitting curve, as shown in Figure 22(b).

\section{Conclusion}

This article presents a series of field measuring data of adjacent existing structures (including tunnels and piles) and ground surface during enlarging the existing rectangular underpass. The study focuses on the structural deformation that is more concerned in engineering and provides experience for similar projects in the future. The following conclusions can be summarized from this study:

(1) Based on the specific condition in this study, the Gaussian distribution curve and its superposition method are applicable for case of enlarging the rectangular tunnel.

(2) The Gaussian distribution curve can also be applied to the heave deformation caused by tunneling.

(3) Due to the lack of theoretical research, the tangent function is proposed to be suitable for the settlement of piled foundation affected by enlarging the rectangular tunnel.

(4) The geometry of a rectangular tunnel may have an additional effect on the deformation of surrounding structures.

\section{Data Availability}

The data used to support the findings of this study are included within the article.

\section{Conflicts of Interest}

The authors declare that there are no conflicts of interest regarding the publication of this paper.

\section{Acknowledgments}

The research work described in this paper has been funded by the National Key R\&D Program of China (Grant no. 2017YFC0805306) and the National Nature Science Foundation of China (NSFC) (Grant no. 41702287). These financial supports are gratefully acknowledged.

\section{References}

[1] Z. F. Wang, S. L. Shen, and W. C. Cheng, "Simple method to predict ground displacements caused by installing horizontal jet-grouting columns," Mathematical Problems in Engineering, vol. 2018, Article ID 1897394, 11 pages, 2018.

[2] Z. F. Wang, W. C. Cheng, and Y. Q. Wang, "Investigation into geohazards during urbanization process of Xi'an, China," Natural Hazards, vol. 92, no. 3, pp. 1937-1953, 2018.

[3] Z. F. Wang, W. C. Cheng, and Y. Q. Wang, "Simple method to predict settlement of composite foundation under embankment," International Journal of Geomechanics, vol. 18, no. 12, article 04018158, 2018.

[4] J. L. Qiu, X. L. Wang, J. X. Lai, Q. Zhang, and J. B. Wang, "Response characteristics and preventions for seismic subsidence of loess in Northwest China," Natural Hazards, vol. 92, no. 3, pp. 1909-1935, 2018.

[5] J. L. Qiu, H. Liu, and J. X. Lai, "Investigating the long-term settlement of a tunnel built over improved loessial foundation soil using jet grouting technique," Journal of Performance of Constructed Facilities, vol. 32, no. 5, 2018.

[6] Y. Q. Wang, Z. F. Wang, and W. C. Cheng, "A review on land subsidence caused by groundwater withdrawal in Xi'an, China," Bulletin of Engineering Geology and the Environment, 2018, In press.

[7] R. B. Peck, "Deep excavation and tunneling in soft ground, State of the art report," in Proceedings of 7th International Conference on Soil Mechanics and Foundation Engineering, pp. 225-290, Mexico City, Mexico, 1969.

[8] S. G. Ercelebi, H. Copur, and I. Ocak, "Surface settlement predictions for Istanbul metro tunnels excavated by EPBTBM," Environmental Earth Sciences, vol. 62, no. 2, pp. 357-365, 2011.

[9] S. Divall, R. J. Goodey, and R. N. Taylor, "Ground movements generated by sequential twin-tunnelling in over-consolidated clay," in Proceedings of Eurofuge Conference, Delft, The Netherlands, April 2012.

[10] R. P. Chen, J. Zhu, and W. Liu, "Ground movement induced by parallel EPB tunnels in silty soils," Tunnelling and Underground Space Technology, vol. 26, no. 1, pp. 163-171, 2011.

[11] I. Yamaguchi, I. Yamazaki, and Y. Kiritani, "Study of ground-tunnel interactions of four shield tunnels driven in close proximity, in relation to design and construction of parallel shield tunnels," Tunnelling and Underground Space Technology, vol. 13, no. 3, pp. 289-304, 1998. 
[12] Y. Wei, X. Gao, and S. Liang, "A combined SPM/NI/EDS method to quantify properties of inner and outer C-S-H in OPC and slag-blended cement pastes," Cement and Concrete Composites, vol. 85, pp. 56-66, 2018.

[13] P. Kitiyodom, T. Matsumoto, and K. Kawaguchi, "A simplified analysis method for piled raft foundations subjected to ground movements induced by tunneling," International Journal for Numerical and Analytical Methods in Geomechanics, vol. 29, no. 15, pp. 1485-1507, 2010.

[14] Y. Wei, X. Gao, F. Wang, and Y. Zhang, "Nonlinear strain distribution in a field-instrumented concrete pavement slab in response to environmental effects," Road Materials and Pavement Design, pp. 1-14, 2018, In press.

[15] F. P. Li, F. Wang, and Q. Fang, "Undrained analysis of ground reaction curves for deep tunnels in saturated ground considering the effect of ground reinforcement," Tunnelling and Underground Space Technology, vol. 71, pp. 579-590, 2018.

[16] R. J. Mair, M. J. Gunn, and M. P. O’Reilly, "Ground movements around shallow tunnels in soft clay," in Proceedings of the Tenth ICSMFE, pp. 323-328, Stockholm, Sweden, June 1981.

[17] R. J. Mair, R. N. Taylor, and A. Bracegirdle, "Subsurface settlement profiles above tunnels in clays," Geotechnique, vol. 43, no. 2, pp. 315-320, 1993.

[18] G. W. Byun, D. G. Kim, and S. D Lee, "Behavior of the ground in rectangularly crossed area due to tunnel excavation under the existing tunnel," Tunnelling and Underground Space Technology, vol. 21, no. 3-4, p. 361, 2006.

[19] G. Giardina, M. J. D. Jong, and R. J. Mair, "Interaction between surface structures and tunnelling in sand: centrifuge and computational modelling," Tunnelling and Underground Space Technology, vol. 50, pp. 465-478, 2015.

[20] Z. Wang, R. Wong, and S. Li, "Finite element analysis of longterm surface settlement above a shallow tunnel in soft ground," Tunnelling and Underground Space Technology, vol. 30, pp. 85-92, 2012.

[21] A. M. Hefny, H. C. Chua, and J. Jhao, "Parametric studies on the interaction between existing and new bored tunnels," Tunnelling and Underground Space Technology, vol. 19, no. 45, p. 471, 2004.

[22] S. H. Kim, H. J. Burd, and G. W. E. Milligan, "Interaction between closely spaced tunnel in clay," in Proceedings of International Symposium on Geotechnical Aspects of Underground Construction in Soft Ground, pp. 543-548, London, UK, April 1996.

[23] S. Macklin, "The prediction of volume loss due to tunneling in overconsolidated clay based on heading geometry and stability number," Ground Engineering, vol. 32, no. 4, pp. 30-33, 1999.

[24] R. Liang, T. D. Xia, and Y. Hong, "Effects of above-crossing tunnelling on the existing shield tunnels," Tunnelling and Underground Space Technology, vol. 58, pp. 159-176, 2016.

[25] N. A. Do, D. Dias, and P. Oreste, "Three-dimensional numerical simulation of a mechanized twin tunnels in soft ground," Tunnelling and Underground Space Technology, vol. 42 , pp. $40-51,2014$.

[26] J. I. Choi and S. W. Lee, "Influence of existing tunnel on mechanical behavior of new tunnel," KSCE Journal of Civil Engineering, vol. 14, no. 5, pp. 773-783, 2010.

[27] C. W. W. Ng, K. M. Lee, and D. K. W. Tang, "Threedimensional numerical investigations of new Austrian tunnelling method (NATM) twin tunnel interactions," Canadian Geotechnical Journal, vol. 41, no. 3, pp. 523-539, 2014.
[28] J. P. Kimmance, S. Lawrence, and O. Hassan, "Observations of deformations created in existing tunnels by adjacent and cross cutting excavations," Geotechnical Aspects of Underground Construction in Soft Ground, pp. 707-712, 1996, In press.

[29] X. Bian, Y. P. Cao, and Z. F. Wang, "Effect of super-absorbent polymer on the undrained shear behavior of cemented dredged clay with high water content," Journal of Materials in Civil Engineering, vol. 29, no. 7, 2017.

[30] X. Bian, Y. J. Cui, and X. Z. Li, "Voids effect on the swelling behaviour of compacted bentonite," Geotechnique, pp. 1-13, 2018, In press.

[31] J. X. Lai, S. Y. He, and J. L. Qiu, "Characteristics of Seismic disasters and aseismic measures of tunnels in Wenchuan earthquake," Environmental Earth Sciences, vol. 76, no. 2, pp. 76-94, 2017.

[32] J. X. Lai, K. Y. Wang, J. L. Qiu, F. Y. Niu, J. B. Wang, and J. X. Chen, "Vibration response characteristics of the cross tunnel structure," Shock and Vibration, vol. 2016, Article ID 9524206, 16 pages, 2016.

[33] J. L. Qiu, X. L. Wang, and S. Y. He, "The catastrophic landside in Maoxian County, Sichuan, SW China on June 24," Natural Hazards, vol. 89, no. 3, pp. 1485-1493, 2017.

[34] L. T. Chen, H. G. Poulos, and N. Loganathan, "Pile responses caused by tunneling," Journal of Geotechnical and Geoenvironmental Engineering, vol. 125, no. 3, pp. 207-215, 1999.

[35] C. J. Lee, "Three-dimensional numerical analyses of the response of a single pile and pile groups to tunnelling in weak weathered rock," Tunnelling and Underground Space Technology, vol. 32, pp. 132-142, 2012.

[36] H. Mroueh and I. Shahrour, "Three-dimensional finite element analysis of the interaction between tunneling and pile foundations," International Journal for Numerical and Analytical Methods in Geomechanics, vol. 26, no. 3, pp. 217-230, 2010.

[37] Y. Q. Li, K. H. Xie, and J. Zhou, "Analysis of the factors influencing foundation pit deformations," Geotechnical Aspects of Underground Construction in Soft Ground, pp. 153-158, 2018, In press.

[38] P. Jongpradist, T. Kaewsri, and A. Sawatparnich, "Development of tunneling influence zones for adjacent pile foundations by numerical analyses," Tunnelling and Underground Space Technology, vol. 34, no. 1, pp. 96-109, 2013.

[39] P. Lueprasert, P. Jongpradist, and P. Jongpradist, "Numerical investigation of tunnel deformation due to adjacent loaded pile and pile-soil-tunnel interaction," Tunnelling and Underground Space Technology, vol. 70, pp. 166-181, 2017.

[40] A. M. Marshall, Tunnelling in sand and its effect on pipelines and piles, Ph.D thesis, Cambridge University, Cambridge, UK, 2009.

[41] A. M. Marshall, "Tunnel-pile interaction analysis using cavity expansion methods," Journal of Geotechnical and Geoenvironmental Engineering, vol. 138, no. 10, pp. 1237-1246, 2012.

[42] A. M. Marshall, “"Closure to "Tunnel-pile interaction analysis using cavity expansion methods" by Alec M. Marshall," Journal of Geotechnical and Geoenvironmental Engineering, vol. 9, no. 11, pp. 2002-2004, 2013.

[43] A. M. Marshall and T. Haji, "An analytical study of tunnel-pile interaction," Tunnelling and Underground Space Technology, vol. 45, no. 5, pp. 43-51, 2015.

[44] C. W. W. Ng, H. Lu, and S. Y. Peng, “Three-dimensional centrifuge modelling of the effects of twin tunnelling on an 
existing pile," Tunnelling and Underground Space Technology, vol. 35, no. 4, pp. 189-199, 2013.

[45] Y. J. Lee and R. H. Bassett, "Influence zones for 2D pile-soiltunnelling interaction based on model test and numerical analysis," Tunnelling and Underground Space Technology, vol. 22, no. 3, pp. 325-342, 2007.

[46] D. Selemetas, J. R. Standing, and R. J. Mair, "The response of full-scale piles to tunneling," Geotechnical Aspects of underground Construction in Soft Ground, pp. 763-769, 2005, In press.

[47] N. N. He, P. Li, and S. J. Shao, "Ground settlement monitoring above Xi'an Metro tunnel through the saturated soft loess," Journal of Earth Sciences and Environment, vol. 34, no. 1, pp. 100-107, 2012.

[48] Z. C. Wang, Z. Hu, J. X. Lai, H. Wang, K. Wang, and W. B. Zan, "Settlement characteristics of jacked box tunneling underneath a highway embankment," Journal of Performance of Constructed Facilities, 2018, In press.

[49] D. V. L. Hunt, Predicting the ground movements above twin tunnels constructed in London clay, Ph.D. Thesis, University of Birmingham, Birmingham, UK, 2005.

[50] R. Ren, H. Zhou, Z. Hu, S. Y. He, and X. L. Wang, "Statistical analysis of fire accidents in Chinese highway tunnels 20002016," Tunnelling and Underground Space Technology, 2018, In press.

[51] N. D. Chapman, S. K. Ahn, and D. V. L. Hunt, "Investigating ground movements caused by the construction of multiple tunnels in soft ground using laboratory model tests," Canadian Geotechnical Journal, vol. 44, no. 6, pp. 631-643, 2007.

[52] Y. C. Zheng, K. Liu, Y. Fang, W. S. Zhang, and J. Fang, "Rockburst prediction model based on entropy weight integrated with grey relational-BP neural network," Advances in Civil Engineering, 2018, In press.

[53] S. Suwansawat and H. H. Einstein, "Describing settlement troughs over twin tunnels using a superposition technique," Journal of Geotechnical and Geoenvironmental Engineering, vol. 133, no. 4, pp. 445-468, 2007.

[54] R. Ren, S. S. Xu, Z. D. Ren et al., "Numerical investigation of particle concentration distribution characteristics in twintunnel complementary ventilation system," Mathematical Problems in Engineering, vol. 2018, Article ID 1329187, 13 pages, 2018.

[55] J. X. Lai, X. L. Wang, J. L. Qiu, J. X. Chen, Z. N. Hu, and H. Wang, "Extreme deformation characteristics and countermeasures for a tunnel in difficult grounds in southern Shaanxi, China," Environmental Earth Sciences, vol. 77, no. 19, 2018.

[56] R. Ren, D. Q. Yu, L. X. Wang, K. Wang, H. Wang, and S. Y. He, "Typhoon triggered operation tunnel debris flow disaster in coastal areas of SE China," Geomatics, Natural Hazards and Risk, 2018, In press.

[57] L. Chen, H. Huang, and R. Wang, "Analysis of the observed longitudinal settlement of a tunnel caused by an adjacent shield tunneling on top," China Civil Engineering Journal, vol. 39, pp. 83-87, 2006, in Chinese.

[58] C. Ding and X. Yang, "Influence analysis on shield tunnel upcrossing nearby built tunnel," Construction Technology, vol. 38, pp. 48-50, 2009, in Chinese.

[59] L. Zhu and H. Huang, "Monitoring data analysis of disturbing effect caused by shield-driven over operating tunnel," Journal of Zhejiang University, vol. 44, no. 10, pp. 1962-1967, 2010, in Chinese. 


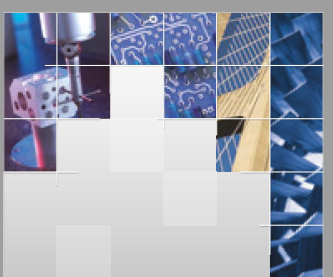

\section{Enfincering}
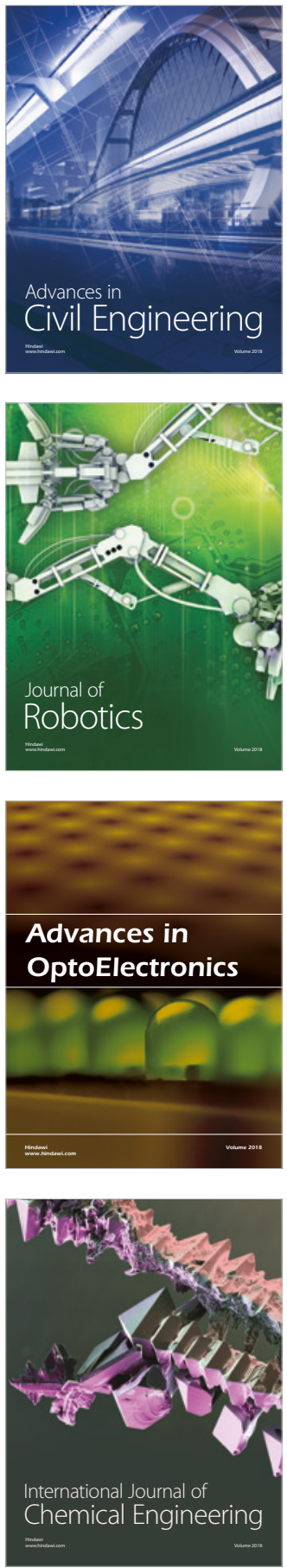

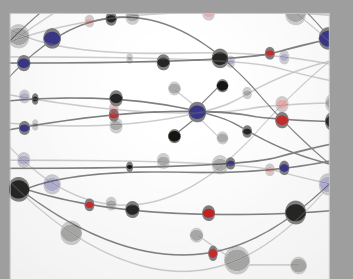

\section{Rotating \\ Machinery}

The Scientific World Journal

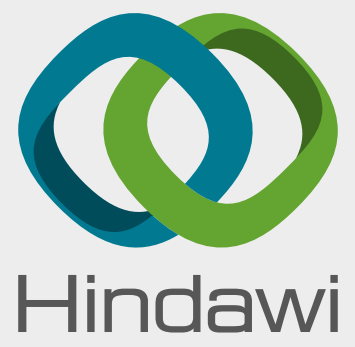

Submit your manuscripts at

www.hindawi.com
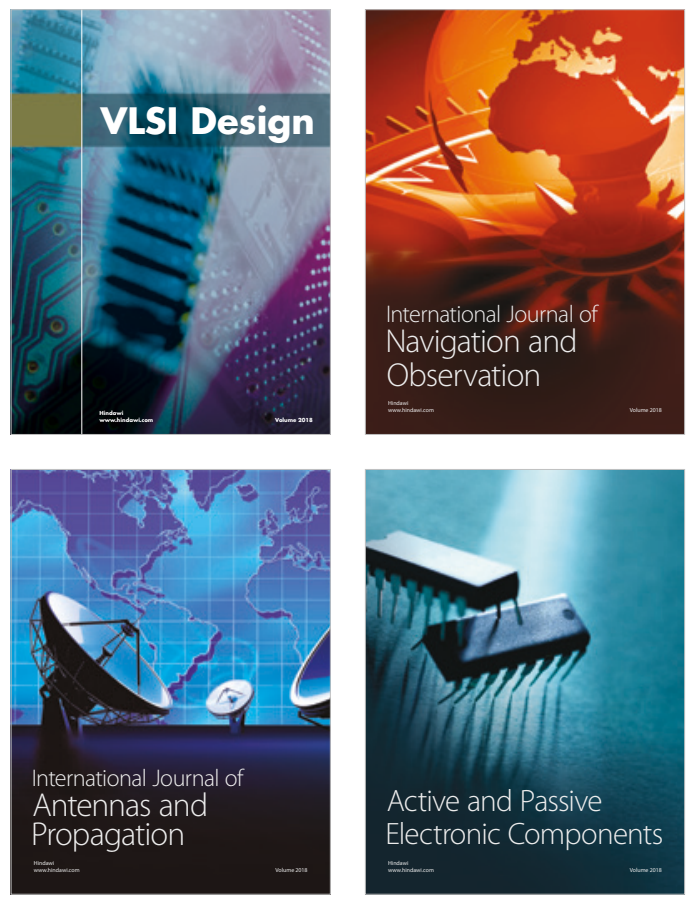
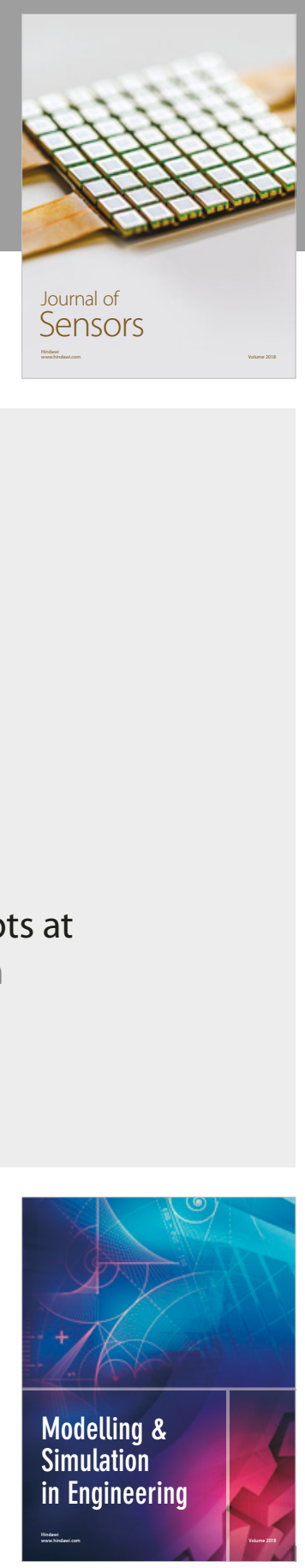

\section{Advances \\ Multimedia}
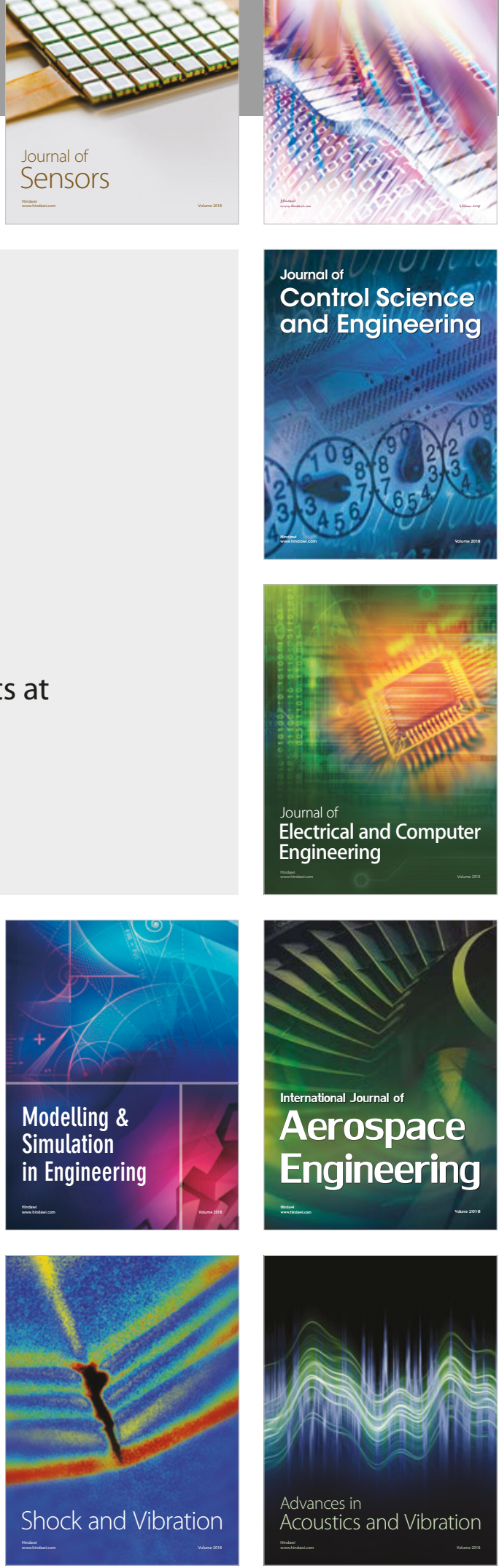